\title{
A Biosystematic and Morphometric Investigation of the Characters of Rodents (Mammalia: Rodentia) as Reservoir Hosts for Zoonotic Cutaneous Leishmaniasis in an Endemic Focus of Sistan-Baluchistan Province, Iran
}

\author{
Hamid Kassiri ${ }^{1}$; Mona Sharififard ${ }^{1, *}$ \\ ${ }^{1}$ Department of Medical Entomology and Vector Health, School of Health, Ahvaz Jundishapur University of Medical Sciences, Ahvaz, IR Iran \\ *Corresponding author: Mona Sharififard, School of Health, Ahvaz Jundishapur University of Medical Sciences, Ahvaz, IR Iran. Tel: +98-611336754350, Fax: +98-6113738282, E-mail: \\ sharififardm@yahoo.com
}

Received: March 10, 2014; Revised: December 2, 2014; Accepted: December 28, 2014

\begin{abstract}
Background: Rodents play a major role in economic losses and public health problems. These animals are considered as natural reservoir hosts of Zoonotic Cutaneous Leishmaniasis (ZCL), one of the major health concerns in Iran.

Objectives: This research was aimed to study rodents' diversity and faunistic of Chabahar County, Sistan-Baluchistan Province, Southeastern Iran, as an old ZCL focus.

Materials and Methods: Trappings were randomly performed with 20 Sherman live-traps at four localities from Chabahar County, continuously during 5 months. In the laboratory, the animal skin was entirely removed and taxidermy was performed. Four standard external characters and seven cranial variables were measured using a ruler and vernier calipers, respectively. The collected specimens were identified with respect to their morphological, external, cranial and dental characteristics. A relevant key was used for identification. Sampling was performed in different places from vegetation covering around rodent burrows.

Results: Seven species belonging to two families, Muridae and Sciuridae, were collected and determined. A total of seventy individuals of rodents, Meriones hurrianae (M. hurrianae) Jordon 1867, Tatera indica (T. indica) Hardwicke 1807, Mus musculus (M. musculus) Linnaeus 1758, Rattus norvegicus (R. norvegicus) Berkenhout1769, Rattus rattus (R. rattus) Linnaeus 1758, Nesokia indica (N. indica) Gray 1830 and Funambulus pennantii (F.pennantii) Wroughton 1905, were trapped. The majority (78.6\%) of the study specimens comprised of M. hurrianae and T. indica. These two species were found in all study areas, with high abundance. They live socially in large parts of area lands, with a very large number of rodent burrows. Standard external morphologic and morphometric characters of M. hurrianae and T. indica, including cranial and dental, are given.
\end{abstract}

Conclusions: The spatial and temporal monitoring of wild rodents will help to predict the potential zoonotic rodent-borne diseases.

Keywords: Rodentia; Diversity; Ecology; Cutaneous Leishmaniasis; Fauna; Iran

\section{Background}

Due to important impact of rodents in human life, including spread of diseases, monetary loss by destroying foodstuffs and materials, their importance in laboratory research, particularly medical research, and also, because of the high diversity and distribution of this animal order, rodents' fauna and diversity of each area is necessary to determine. Numerous studies have been performed on rodents' fauna in different areas in Iran (1-8).

Cutaneous leishmaniasis (CL) is a global major public health concern and affects over 12 million people in multiple regions of the world (9). Immigration of nonimmune people to endemic regions, population growth, activity of infected rodents and sand flies, persons overtaken from lesions, have provided an appropriate environment for the maintenance of the CL (10). The major health problems of rodents are their role as natural reservoir hosts of zoonotic diseases. Leishmaniasis is the most important disease caused in humans, with more than 20 species of Leishmania (L.) and transmitted by nearly 30 species of sand flies. Generally, CL has been distributed in Iran in recent decades. It is endemic in 15 out of the 31 provinces of the country and sporadic in other areas $(1,11$, 12). Lately, several new foci of CL have been reported, indicating the potential spread of the disease in Iran. Both epidemiological forms of CL are present in the country; Zoonotic CL (ZCL), caused by L. major and anthroponotic CL (ACL) caused by L. tropica. In a new focus of CL in Poledokhtar District, the results of polymerase chain reaction (PCR) assays indicated that $96.15 \%$ of cases were L. major, whereas 3.85\% were L. tropica (13-15). The ZCL is one of the infectious diseases expanding in Iran, where it almost doubled (from 11505 to 22705 cases) over a 9-year period, from 2001 to 2009 (11). Multiple rodents have been identified as reservoir hosts of ZCL in different areas of Iran. For

Copyright (c) 2015, Infectious Diseases and Tropical Medicine Research Center. This is an open-access article distributed under the terms of the Creative Commons Attribution-NonCommercial 4.0 International License (http://creativecommons.org/licenses/by-nc/4.0/) which permits copy and redistribute the material just in noncommercial usages, provided the original work is properly cited. 
example, Rhombymus opimus (R. opimus) has been known as the primary reservoir in Central, North, North Eastern Iran $(8,16)$. In South, West and Southwestern Iran, Tatera indica (T. indica) murines act as primary hosts along with Nesokia indica (N. indica) and Meriones libycus (M. libycus), as the secondary hosts (17-19). In Roffaye District, Southwest of Iran, the PCR technique showed that T. indica was positive for the L. major parasite (20). In Fars Province, Southern Iran, results of PCR indicated that Rattus norvegicus (R. norvegicus) was infected with L. major. This species can be considered as a possible reservoir in transmission of the disease in Fars Province. In this province, Meriones libycus (M. libycus) was reported as the main reservoir of ZCL in Arsanjan and Marvdasht cities, and T. indica and Gerbillus spp. were the reservoirs reported in Larestan and Kharameh districts (21-23). The Sistan-Baluchistan Province, Southeastern Iran, is considered as the focus of ZCL in Iran (24-26) and the disease has become a major health problem in rural areas of Chabahar and Mirjaveh Counties of this province, as old foci of the disease. Meriones hurrianae (M. hurrianae) and T. indica were determined as primary and secondary reservoir hosts in the Chabahar focus, respectively $(25,27)$. In this region, Leishmania DNA isolated from $M$. hurrianae produced distinctive bands of L. major with four primers (28). Phlebotomus papatasi ( $P$. papatasi) and P. salehi (Diptera: Psychodidae: Phlebotominae) are the dominant Phlebotomus species and they are reported as the main and secondary vectors of ZCL in this focus, respectively $(26,29)$. In this area, $P$. papatasi and $P$. salehi, were found to be infected with L. major with Random Amplified Polymorphic DNA - PCR (RAPD-PCR) assay (29).

\section{Objectives}

This study was aimed to identify the rodents' fauna and diversity of Chabahar County. The morphometric and morphologic measurements were performed just on $M$. hurrianae and T. indica, as main and secondary reservoir hosts in Chabahar County.

\section{Materials and Methods}

Wild rodents were collected fortnight using Sherman live traps, placed in several choice colonies in rural areas of Negor, Plan and Nobandian, as well Chabahar City, from the Chabahar County. These rural areas were located in Dashtyari District in Chabahar County. Suitable baits including cucumber pieces, tomato, roasted almond and date were used in the traps. A total of 20 live traps were placed at the entrance of active and constant rodent colonies, at each sampling. The traps were installed at sunset and collected before sunrise. Also, sampling was performed in different places from plant covering around rodent burrows.

The collective rodents were anesthetized using a cotton piece soaked in chloroform in buccal glass. Four standard external characters including Head-Body Length (HBL),
Tail Length (TL), Ear Length (EL) and Hind Foot Length (HFL) were measured using a ruler. The animal skin was completely removed and taxidermy was done in the laboratory. For cranial measurements, rodent skull was boiled in $100 \mathrm{ml}$ distilled water with 4 drops $\mathrm{NaOH} 10 \%$. The skin and muscles were isolated and the skull was exposed to hydrogen peroxide for 25 minutes to dissolve the fats and whiten the skull. Finally, cranial variables including: Occipitonasal Length (OL), Condylobasal Length (CL), Zygomatic Width (ZW), Least Interorbital Width (LIW), Length of Tympanic Bullae (LTB), Length of Upper Molars (LUM), Length of Lower Molars (LLM) were measured using the Vernier calipers. Family, genus and species of rodents were identified using a rodent relevant key.

\section{Results}

The study area was mostly a desert landscape due to minimal rainfall, with a high relative humidity because of proximity to the sea. Moisture average was $50-70 \%$ in winter and 70-87\% in summer and spring. This area has a sandy-clay and relatively soft soil. Totally 600 traps were installed during the study period. Seventy rodents belonging to seven species, six genera and two families were collected. Six species were in Muridae (Gerbillinae and Murinae subfamilies) and suborder Myomorpha, as well one species in Sciuridae and suborder Sciuromorpha. The captured species and their frequency (\%) are shown in Figures 1 and 2 (A-G). Meriones hurrianae and T. indica comprised the most specimens of this study (78.6\%).

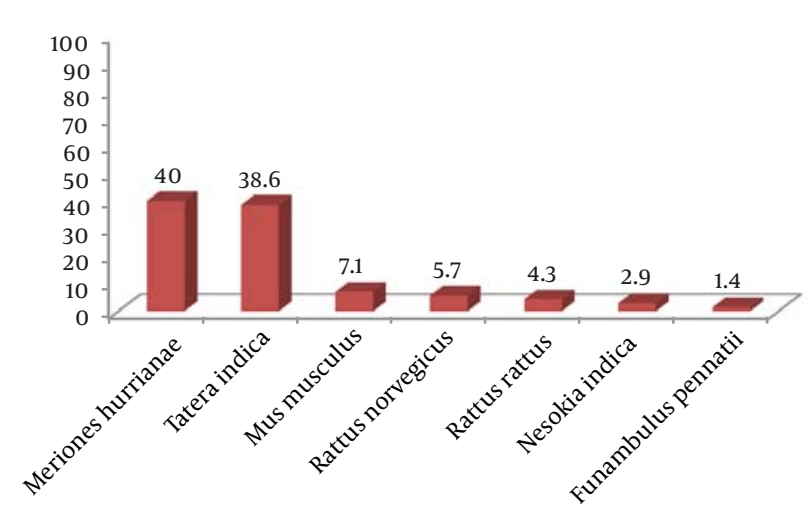

Figure 1. Rates of Rodents Species Collected From Chabahar County, Sistan-Baluchistan Province, Southeast Iran

The T. indica has a hairy tail. The hairs are a little longer at the end and gives small terminal hair gangs (Figure 2 A). Ears are relatively large and oval in shape. The muzzle is long and the ends of the nasal bones have been prolonged up to the front of upper incisors. The color of the body dorsal surface is brown buff. Upper incisors have an orange middle groove on the anterior surface. These teeth have extended downwards and backwards. The size of the first molar is more than twice that of the other molars, overall. There are three cross bands at the surface of 

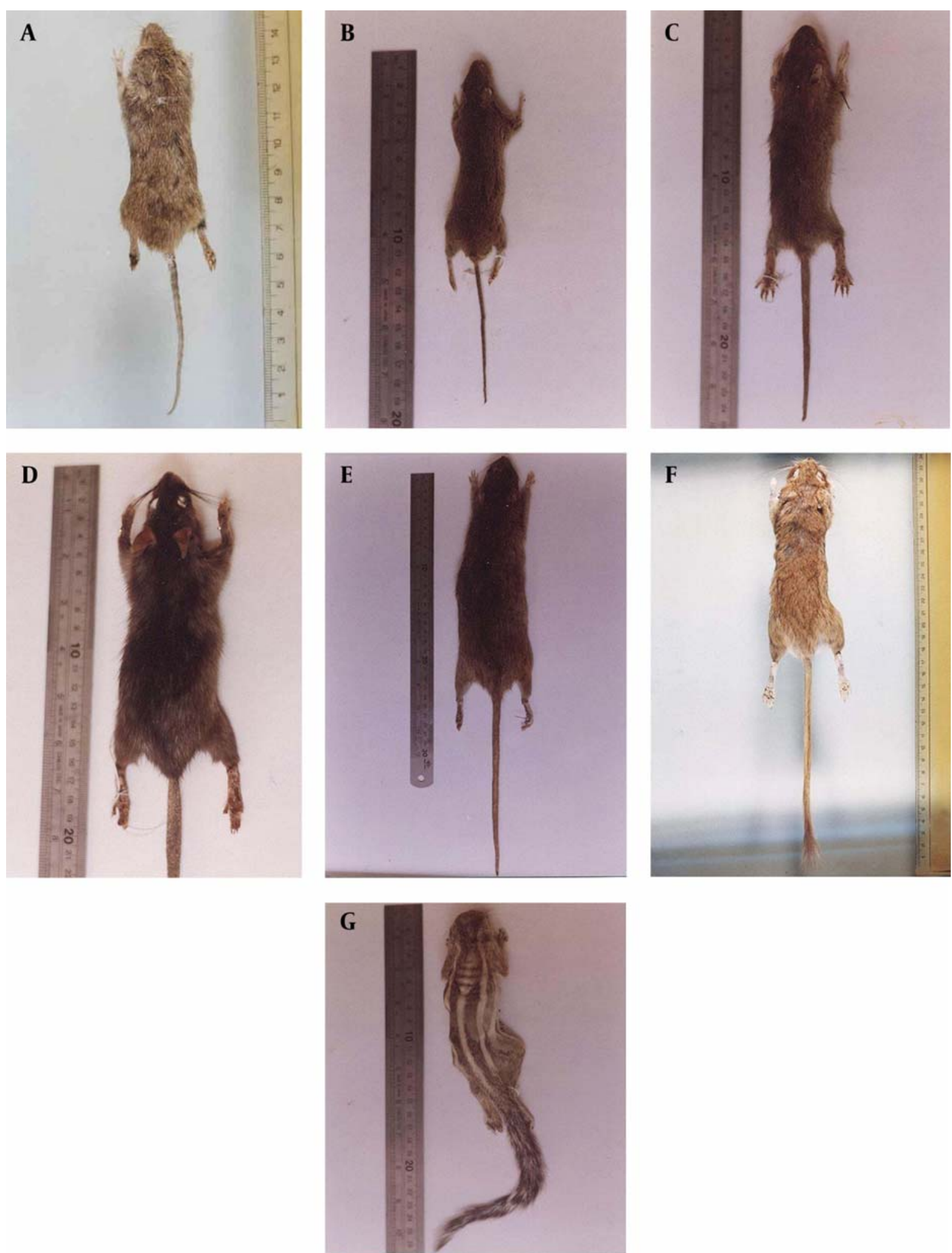

Figure 2. A) Meriones hurrianae, B) Mus musculus, C) Nesokia indica, D) Rattus norvegicus, E) Rattus rattus, F) Tatera indica, G) Funambulus pennantii

the first molar (these three bands were not connected together) (Figures $3 \mathrm{~A}$ and $4 \mathrm{~A}$ ), while the cross bands at the first molar were connected together in M. hurrianae (the three grooves were connected by a bridge). The second molar has two cross bands and it is twice as large as the the third molar. The third molar is the smallest and has two 
Kassiri Het al.

cross bands, and it has a triangular shape. Tatera indica is nocturnal and is not used to living in dry areas and is often seen near the fields and human dwellings. Its external and cranial measurements are shown in the Tables 1,2 and 3.

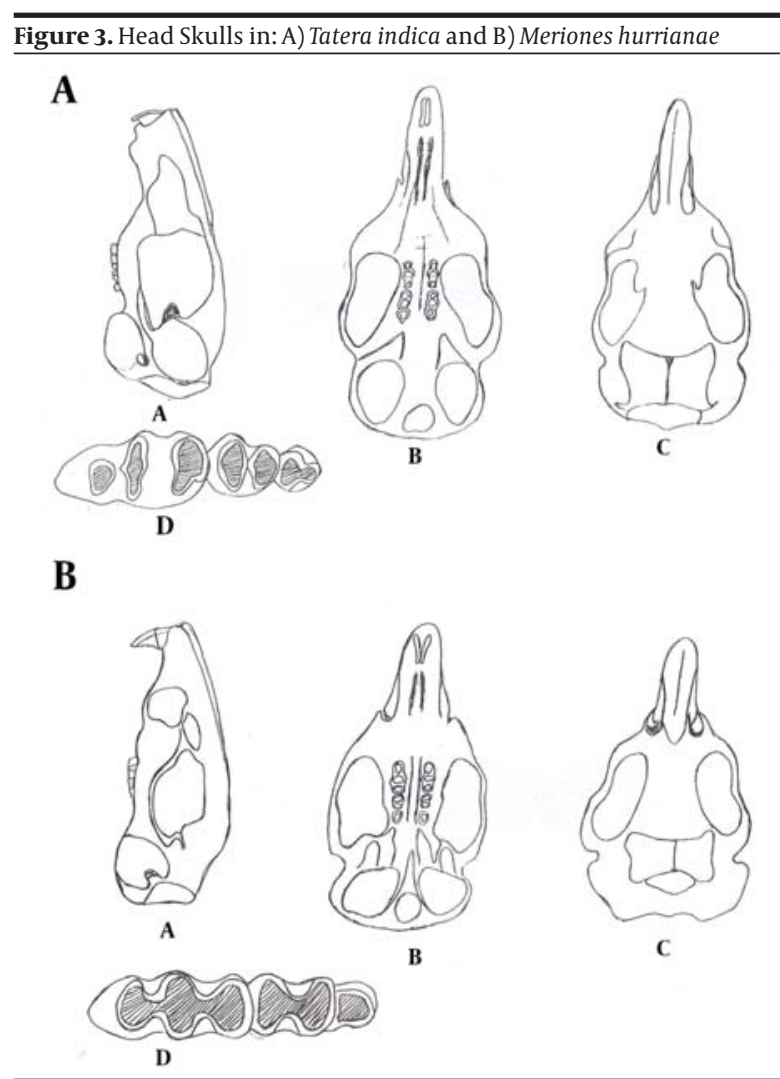

A: Lateral view, B: Ventral View, C: Dorsal View, D: Molars in Right Half of Mandible (Specimens Collected From Dashtyari District, Chahbahar County).

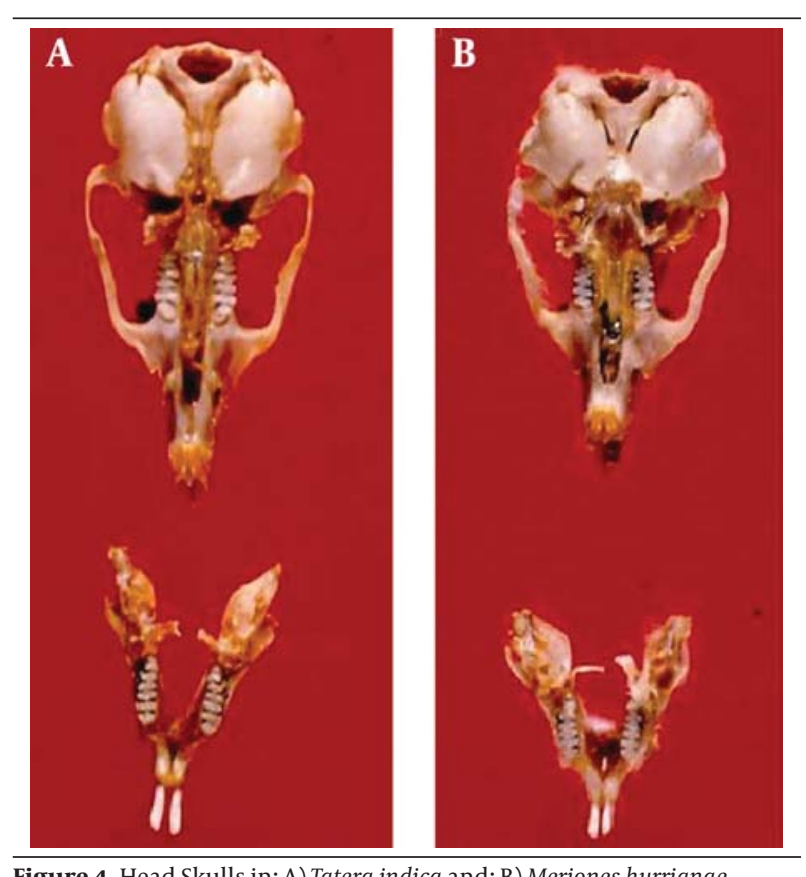

Figure 4. Head Skulls in: A) Tatera indica and; B) Meriones hurrianae
Table 1. External Measurements of Meriones hurrianae Collected From Chabahar County, Sistan-Baluchistan Province, Southeast Iran $^{\mathrm{a}, \mathrm{b}}$

\begin{tabular}{|c|c|c|c|c|}
\hline No. & $H B L$ & $T L$ & $E L$ & $H F L$ \\
\hline 1 & 125 & 143 & 13 & 32 \\
\hline 2 & 130 & 145 & 11 & 31.5 \\
\hline 3 & 135 & 142 & 12 & 29 \\
\hline 4 & 132 & 134 & 10 & 30 \\
\hline 5 & 134 & 139 & 10 & 30 \\
\hline 6 & 138 & 148 & 9 & 30.5 \\
\hline 7 & 150 & 146 & 10 & 33 \\
\hline 8 & 141 & 146 & 10 & 31 \\
\hline 9 & 127 & 134 & 11 & 28.5 \\
\hline 10 & 150 & 142 & 11 & 29 \\
\hline 11 & 153 & 145 & 12 & 31.5 \\
\hline 12 & 157 & 143 & 11 & 31 \\
\hline 13 & 148 & 132 & 12 & 29 \\
\hline 14 & 138 & 135 & 10 & 32 \\
\hline 15 & 151 & 145 & 12 & 32.5 \\
\hline 16 & 157 & 149 & 11 & 33 \\
\hline 17 & 142 & 146 & 11 & 30.5 \\
\hline 18 & 150 & 147 & 10 & 31 \\
\hline 19 & 138 & 135 & 11 & 29.5 \\
\hline 20 & 132 & 139 & 12.5 & 30.5 \\
\hline Mean $\pm S D$ & $140.9 \pm 19.8$ & $141.7 \pm 10.4$ & $10.9 \pm 2$ & $30.75 \pm 2.4$ \\
\hline
\end{tabular}
$\mathrm{a}$ All Values are Presented as mm.
$\mathrm{b}$ Abbreviations: EL, ear Length; HBL, Head-Body Length; HFL, Hind Foot
Length; TL, Total Length.

Table 2. External Measurements of Tatera indica Collected From Chabahar County, Sistan-Baluchistan Province, Southeast Iran a, b

\begin{tabular}{lcccc}
\hline No. & $H B L$ & $T L$ & $E L$ & $H F L$ \\
\hline $\mathbf{1}$ & 149 & 153 & 22 & 36 \\
$\mathbf{2}$ & 159 & 168 & 22 & 36 \\
$\mathbf{3}$ & 157 & 164 & 22 & 34 \\
$\mathbf{4}$ & 150 & 153 & 22 & 38 \\
$\mathbf{5}$ & 156 & 163 & 27 & 37 \\
$\mathbf{6}$ & 162 & 169 & 22 & 36 \\
$\mathbf{7}$ & 159 & 162 & 21 & 39 \\
$\mathbf{8}$ & 155 & 165 & 21 & 37 \\
$\mathbf{9}$ & 157 & 154 & 23 & 36 \\
$\mathbf{1 0}$ & 159 & 152 & 21 & 36 \\
$\mathbf{1 1}$ & 162 & 158 & 19 & 36 \\
$\mathbf{1 2}$ & 150 & 170 & 20 & 35 \\
$\mathbf{1 3}$ & 162 & 169 & 21 & 36 \\
$\mathbf{1 4}$ & 163.5 & 161 & 18 & 36 \\
$\mathbf{1 5}$ & 159 & 179 & 18 & 36 \\
$\mathbf{1 6}$ & 156 & 159 & 22 & 35 \\
$\mathbf{1 7}$ & 157 & 154 & 23.5 & 35.5 \\
\hline Mean \pm SD & $156.7 \pm 9.6$ & $161.9 \pm 15$ & $21.4 \pm 4.2$ & $36.1 \pm 2.4$ \\
\hline
\end{tabular}

${ }^{\mathrm{a}}$ All Values are Presented as $\mathrm{mm}$.

b Abbreviations: EL, ear Length; HBL, Head-Body Length; HFL, Hind Foot Length; TL, Total Length. 
Kassiri H et al.

Table 3. Cranial Measurements of two Meriones hurrianae and two Tatera indica Collected From Chabahar County, Sistan-Baluchistan Province, Southeast Iran a, b

\begin{tabular}{|c|c|c|c|c|c|c|c|}
\hline Rodents & OL & CL & ZW & LW & LTB & UML & LML \\
\hline Meriones hurrianae (1) & 37.4 & 34.8 & 21.5 & 6.7 & 12.8 & 5.9 & 6.2 \\
\hline Meriones hurrianae (1) & 36.9 & 34.7 & 21.4 & 6.8 & 12.7 & 6.1 & 6.3 \\
\hline Tatera indica (1) & 43.1 & 38.5 & 23.2 & 6.8 & 12.9 & 6.8 & 6.5 \\
\hline Tatera indica (2) & 42.7 & 38.4 & 22.9 & 6.7 & 12.7 & 6.5 & 6.2 \\
\hline
\end{tabular}

Meriones hurrianae with grey appearance has short and somewhat triangular shape ears and short muzzle (Figure $2 \mathrm{~B}$ ). The eyes are relatively small. A mild brush like is formed at the end of the tail. Incisors in mandible are orange at the front surface with a middle longitudinal groove and they have extended back and down. The first molar is larger than the second and third, overall. There are three oval cross bands at the surface of the first molar. The second molar has two cross bands (Figures $3 \mathrm{~B}$ and $4 \mathrm{~B}$ ). The third one is very small with semicircular shape and somewhat angular shapes in the front and behind surfaces, respectively. The muzzle is short and nearly narrow and the ends of the nasal bones have been prolonged up to the front of upper incisors. The M. hurrianae is a diurnal rodent and makes nest in sandy and soft lands. The hottest hours of the day are spent in the nest. Its external and cranial measurements are shown in the Tables 1,2 and 3. Head skulls of M. hurrianae and T. indica captured from Dashtyari District, Chabahar County, and their distribution in Iran are shown in Figures 4 and 5.

The vegetation collected around rodent's nests consists mainly of seven thermophilous species, namely Aerva persica (Amaranthaceae), Amaranthus retroflexus (Amaranthaceae), Cenchrus pennicetiformis (Graminae), Chenopodium morale (Chenopodiaceae), Salsola dendriodes (Chenopodiaceae), Saueda fruticosa (Chenopodiaceae) and Spergula fallax (Paranychiaceae). Both the $M$. hurrianae and T. indica were feed of salt-loving plants, particularly Saueda fruticosa and Salsola dendrioides, from the Chenopodiaceae family.

\section{Discussion}

The results show that seven species of rodents are active in the study area, which represents a considerable rodent fauna of the area. Since $78.6 \%$ of total rodent frequency was related to M. hurrianae and T. indica, the discussion will focus mainly on the results obtained from the morphometric studies of these two species.

About 80 species of rodents occur in Iran (6). Six species belonging tofivegenera, five subfamilies and four families
A

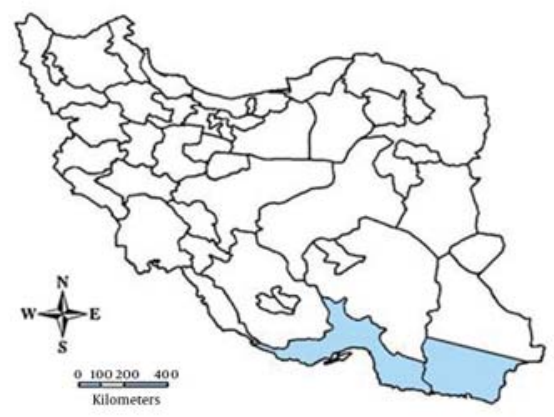

B

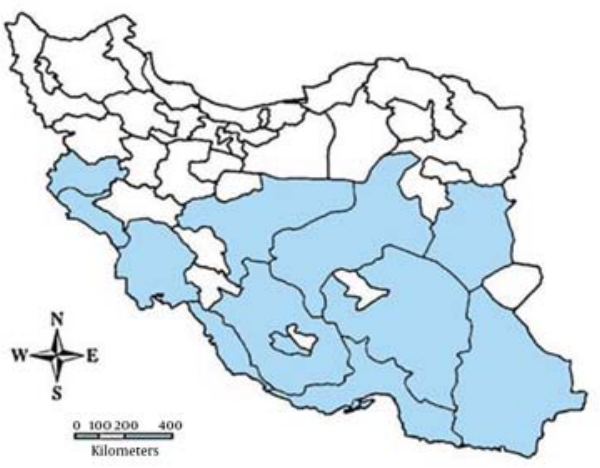

Figure 5. Distribution of A) Meriones hurrianae and B) Tatera indica in Iran

were collected during a faunistic survey of the rodents in Anjerek, prohibited hunting area in the Kerman Province, Southeastern Iran. They were as follows: Mus musculus (M. Musculus), Calamyscus bailwardi, Meriones persicus (M. persicus), M. libycus, Cricetulus migratorius and Dryomys nitedula (6). In the another study, a total of 67 individuals of rodents including: T. indica, M. hurrianae, M. libycus and Gerbillus nanus (G. nanus) were trapped in three areas, Bampor, Daman and Qasre-qand from Iranshahr and Nikshahr Districts, Sistan-Baluchistan Province, Southeastern Iran, during 2008-2009 (7). In a diversity study of the rodents of Northeastern Iran, 26 different species attributing to six families were collected: Sciuridae (Spermophilus fulvus), Cricetidae (Microtus transcaspicus, Microtus paradoxus, Blanfordimys afghanus, Chionomys nivalis, Ellobius talpinus, Ellobius fuscocapillus, Cricetulus migratorius), Calomyscidae (Calomyscus sp. Seems to be C. uratensis), Muridae (M. musculus, Apodemus witherbyi, N. indica, R. norvegicus, Rattus pyctoris, G. nanus, M. libycus, Meriones crassus, Meriones meridianus, M. persicus, T. indica, R. opimus), Gliridae (Dryomys nitedula) and Dipodidae (Allactaga elater, Allactaga hotsoni, Jaculus blanfordi, Jaculus thaleri) (2).

In western and southwestern regions of Iran, T. indica is reported as the main reservoir host of Leishmania para- 
site, the infectious agent of ZCL $(17,18,24)$. The distribution of $T$. indica has been reported from Southwest to Southeast Iran, with its upper limit in Isfahan and Yazd provinces (30). This rodent species is identified as the main reservoir of ZCL in Ilam and Khuzestan Provinces, where M. libycus and $N$. indica were identified as the secondary reservoirs (18). In Isfahan Province, as the most important focus for rural CL, R. opimus is the main reservoir host of the disease and T. indica is the secondary reservoir $(24,25,28)$. The Sistan-Baluchistan Province, in Southeast Iran, is considered as another focus of $\operatorname{ZCL}(25,28)$ and the disease has been increased in Chabahar County, as an old focus of ZCL, in recent years. The M. hurrianae and T. indica were determined as primary and secondary reservoirs of the disease in this area, respectively (25), and the Leishmania parasite was isolated naturally from $M$. hurrianae species by Kassiri et al. ( 2013) (28).

The comparison of the collected specimens of $T$. indica from different areas of Iran represents the differences in morphometric measurements. Length means of external characters, including EL, HFL, TL, HBL in specimens collected from northeast of Iran were 10.24,34.49, 136.72 and $141.76 \mathrm{~mm}$ (2), while they were 10.9, 36.1, 161.9, $156.9 \mathrm{~mm}$, respectively, in the specimens of our study area. Also, the means of TL and HBL of T. indica specimens from Shiraz were 131 and $127 \mathrm{~mm}$, respectively (5). These variable results suggested intraspecific variation of size and also a mechanism of speciation and adaptation. The specimens of $T$. indica collected in this study area have a relatively larger size, at least in external view. It can be concluded that climate changes of geographic regions can have a significant impact on morphological and physiological characters of species and may hold the potential to induce emergence or evolution of new subspecies. These new subspecies may have different characteristics from the standpoint of health or economic importance.

The distribution of the Meriones spp. is in the arid belt of North Africa, Middle East and Asia. Due to interspecific and intraspecific variation of size and also mechanism of speciation and adaptation, these taxa are very interesting to study (31). There are eight species of Meriones in the Iranian Plateau, with different kinds of distribution from each other (31). Three species, including M. libycus, $M$. persicus and M. hurrianae have been reported as reservoir hosts of ZCL in Iran. Despite the wide distribution of T. indica in Iran, which represents its efficient adaptation to ecological conditions, M. hurrianae has just been reported in Jask County, Hormozgan Province, neighboring the Sistan-Baluchistan Province and also in Chabahar County, Sistan-Baluchistan Province $(8,25)$. In addition to M. hurrianae; M. libycus and G. nanus have also been collected from Iranshahr and Nikshahr Counties in SistanBaluchistan Province by Nateghpour et al. (2013) (7), while we failed to capture them in our study area (Chabahar County). This could be due to the different climatic and geographical conditions of their study area compared ours. Meriones persicus, T. indica, M. hurrianae and
G. nanus were also trapped from Jask County, Hormozgan Province by Azizi et al. (2011) (8). Leishmania parasite was isolated from M. hurrianae, T. indica and G. nanus using microscopy and molecular methods, while M. persicus was the most prevalent species in the area.

$M$. hurrianae was the most prevalent species in the study area and it has also been identified as a reservoir host of L. major in India and in Pakistan $(28,32)$. But there were no morphometric data recorded on M. hurrianae to compare with the results of this study. These two species were found in all study areas, with high abundance, and living socially in large parts of the area lands with very large number of rodents nest holes. The rodents were active in the same area and they were trapped from adjacent nests, several times. Both species were most active at night, and only M. hurrianae was also active daily (approximately after 9 am).

The results of this research enable us to provide an instruction for the prevention and control of zoonotic diseases in the region for local authorities and in case of emergency situations. According to the results of the fieldwork study, M. hurrianae and T. indica are two completely differentiated rodent species that were collected from an old ZCL focus and they can also be morphologically differentiated.

\section{Acknowledgements}

The authors would like to thank Iranshahr Health Research Center, Chabahar Center of Health Services, Tehran, Iran, and the people of Iranshahr and Chabahar Counties for their excellent assistance in achieving this study. This project received support from the School of Public Health, Tehran University of Medical Sciences, Tehran, Iran.

\section{References}

1. Mehrabani D, Motazedian MH, Hatam GR, Asgari Q, Owji SM, Oryan A. Leishmania major in Tatera indica in Fasa, Southern Iran: Microscopy, Culture, Isoenzyme, PCR and Morphologic Study. Asian J Anim Vet Adv. 2011;6(3):255-64.

2. Darvish J, Siahsarvie R, Mirshamsi O, Keyvanfar N, Hashemi N, Sadeghi Shakib F. Diversity of the rodents of northeast Iran. Int JAgri Biol. 2006;2(1):57-76.

3. Shirani Bidabadi L, Nilforoushzadeh MA, Akhavan AA, Abdoli H, Siadat AH, Jaffary F, et al. Karyosystematic and morphometric characterization of the rodents as reservoir hosts of zoonotic cutaneous leishmaniasis in an endemic focus of Isfahan Province, Iran. J Vector Borne Dis. 2009;46(1):52-6.

4. Ghorbani F, Darvish H, Gholi Kami H, Mirshamsi O. Rodent fauna of the western Golestan province in northeast Iran. Int J Agri Biol. 2010;6(1):37-48.

5. Zarei R, Darvish J, Esmaeili HR, Tarahomi SM.[A Biosystematic survey of Shiraz (Central Part) rodents. Iran].J Bio. 2010;23(4):573-82.

6. Azarpira M, Madjdzadeh SM, Darvish J. A Faunistic study of rodents (Mammalia: Rodentia) in Anjerk prohibited hunting area, Kerman Province. Iran.J Biol. 2012;25(2):240-51.

7. Nateghpour M, Akhavan AA, Hanafi-Bojd AA, Telmadarraiy Z, Ayazian Mavi S, Hosseini-Vasoukolaei N, et al. Wild rodents and their ectoparasites in Baluchistan area, southeast of Iran. Trop Biomed. 2013;30(1):72-7.

8. Azizi K, Davari B, Kalantari M, Fekri S. [Gerbillid Rodents Fauna 
(Muridae: Gerbillinae) and detection of reservoir hosts(s) of Zoonotic Cutaneous leishmaniasis using a Nested-PCR technique in Jask City in Hormozgan Province 2008]. Sci J Kurdistan Univ Med Sci. 2011;16(2):66-76.

9. Saki J, Khademvatan SA. [molecular study on cutaneous leishmaniasis lesions in Khuzestan province (South west of Iran]. JundishapurJ Microbiol. 2011;4(4):283-8.

10. Mahmoodi MR, Mohajery M, Afshari JT, Shakeri MT, Yazdanpanah MJ, Fariba Berenji F, et al. Molecular identification of Leishmania species causing cutaneous leishmaniasis in Mashhad, Iran. Jundishapur J Microbiol. 2010;3(4):195-200.

11. Bakhshi H, Oshaghi MA, Abai MR, Rassi Y, Akhavan AA, Mohebali M, et al. MtDNA CytB Structure of Rhombomys opimus (Rodentia: Gerbellidae), the Main Reservoir of Cutaneous Leishmaniasis in the Borderline of Iran-Turkmenistan. J Arthropod Borne Dis. 2013;7(2):173-84

12. Kassiri H, Shemshad K, Kassiri A, Shojaee S, Sharifinia N, Shemshad M. Clinical laboratory and epidemiological research on cutaneous leishmaniasis in the south west of Iran. Arch Clin Infect Dis. 2012;7(4):128-31.

13. Oshaghi MA, Rasolian M, Shirzadi MR, Mohtarami F, Doosti S. First report on isolation of Leishmania tropica from sandflies of a classical urban Cutaneous leishmaniasis focus in southern Iran. Exp Parasitol. 2010;126(4):445-50.

14. Sharifi I, Poursmaelian S, Aflatoonian MR, Ardakani RF, Mirzaei $\mathrm{M}$, Fekri AR, et al. Emergence of a new focus of anthroponotic cutaneous leishmaniasis due to Leishmania tropica in rural communities of Bam district after the earthquake, Iran. Trop Med Int Health. 2011;16(4):510-3.

15. Beiranvand E, Kalantari M, Rastgar HA, Amraee K. Molecular Identification of Leishmania Species Isolated From Human Cutaneous Leishmaniasis in Poledokhtar District, Lorestan Province, Iran. Jundishapur J Microbiol. 2013;6(6).

16. Nadim A, Faghih M. The epidemiology of cutaneous leishmaniasis in the Isfahan province of Iran. I. The reservoir. II. The human disease. Trans R Soc Trop Med Hyg. 1968;62(4):534-42.

17. Mirzaei A, Rouhani S, Kazerooni P, Farahmand M, Parvizi P. Molecular detection and conventional identification of leishmania species in reservoir hosts of zoonotic cutaneous leishmaniasis in fars province, South of iran. Iran J Parasitol. 2013;8(2):280-8.

18. Yaghoobi-Ershadi M. Phlebotomine Sand Flies (Diptera: Psychodidae) in Iran and their Role on Leishmania Transmission.J Arthropod Borne Dis. 2012;6(1):1-17.

19. Akhavan A, Yaghoobi-Ershadi M, Mirhendi H, Alimohammadian M, Rassi Y, Shareghi N, et al. Molecular epizootiology of rodent leishmaniasis in a hyperendemic area of iran. Iran J Public Health. 2010;39(1):1-7.

20. Vazirianzadeh B, Saki J, Jahanifard E, Zarean M, Amraee K, Nav- id Pour S. Isolation and Identification of Leishmania Species From Sandflies and Rodents Collected From Roffaye District, Khuzestan Province, Southwest of Iran. Jundishapur J Microbiol. 2013;6(6).

21. Mehrabani D, Motazedian MH, Oryan A, Asgari Q, Hatam GR Karamian M. A search for the rodent hosts of Leishmania major in the Larestan region of southern Iran: demonstration of the parasite in Tatera indica and Gerbillus sp., by microscopy, culture and PCR. Ann Trop Med Parasitol. 2007;101(4):315-22.

22. Motazedian MH, Parhizkari M, Mehrabani D, Hatam G, Asgari Q. First detection of Leishmania major in Rattus norvegicus from Fars Province, Southern Iran. Vector Borne Zoonotic Dis. 2010;10(10):969-75.

23. Azizi K, Moemenbellah-Fard MD, Fakoorziba MR, Fekri S. Gerbillus nanus (Rodentia: Muridae): a new reservoir host of Leishmania major. Ann Trop Med Parasitol. 2011;105(6):431-7.

24. Yaghoobi-Ershadi MR, Javadian E. Epidemiological study of reservoir hosts in an endemic area of zoonotic cutaneous leishmaniasis in Iran. Bull World Health Organ. 1996;74(6):587-90.

25. Kassiri H, Javadian E, Abdigoudarzi M. Natural Leishmania infection in Meriones hurrianae and Tatera indica (Rodentia: Cricetidea: Gerbillinae) in Sistan-Baluchistan Province, south-eastern of Iran. Adv Stud Biol. 2011;3(6):247-56.

26. Kassiri H, Javadian E, Hanafi-Bojd AA. Faunistic survey of sand flies (Diptera: Psychodidae) in Chabahar County, southeast of Iran. J Exp Zool India. 2011;14(2):663-6.

27. Kassiri H. Bionomics of phlebotomine sand flies (Diptera: Psychodidae) as vectors of leishmaniasis in the County of Iranshahr, Sistan-Baluchistan Province, Southeast of Iran. Iran J Clin Infect Dis. 2012;6(3):112-6.

28. Kassiri H, Naddaf SR, Javadian E-A, Mohebali M. First report on isolation and characterization of Leishmania major from Meriones hurrianae (Rodentia: Gerbillidae) of a rural cutaneous leishmaniasis focus in South-Eastern Iran. Iran Red Crescent Med J. 2013;15(9):789-93.

29. Kassiri H, Naddaf SR, Mohebali M, Javadian E-A. Molecular Characterization of Leishmania Infection in Sand flies From Sistan Va Baluchistan Province, Southeastern Iran. Jundishapur J Microbiol. 2012;5(2):430-1.

30. Sedaghat MM, Salahi Moghadam A. Mapping the distribution of the important rodents reservoir in Iran. . J Army Univ Med Sci I.R. 2010;8(3):210-23.

31. Darvish J. Morphmetric comparison of fourteen species of the genus Meriones Illiger, (Gerbillinae, Rodentia) from Asia and North Africa. Int J Agri Biol. 2009;15(1):59-77.

32. Gramiccia M, Gradoni L. The current status of zoonotic leishmaniases and approaches to disease control. Int J Parasitol. 2005;35(11-12):1169-80 